\title{
LA REALIDAD QUE VIVE LA JUVENTUD DE AMÉRICA LATINA DESDE EL PUNTO DE VISTA SOCIAL, ECONÓMICO, CULTURAL
}

DOI: https://doi.org/10.52039/seminarios.v51i177.703

Autor: Jorge Boran. CSSp. Ex asesor de Pastoral Juvenil en la Conferencia Nacional de Obispos Brasileños.
Estudia el impacto de la premodernidad, modernidad y postmodernidad en la juventud de América Latina y sus condicionamientos para la Pastoral Vocacional. Importancia de la actitud profética para la valoración de la Iglesia. Factores negativos: el subjetivismo y emoción postmoderna.

\section{INTRODUCCIÓN}

Mi tema es muy amplio y tengo poco tiempo para presentarlo, por lo tanto, decidí estudiarlo a partir de una perspectiva que pudiera, al mismo tiempo, proporcionar elementos importantes de análisis para NUESTRO ENCUENTRO CONJUNTO DE PASTORAL JUVENIL Y PASTORAL VOCACIONAL. Voy a utilizar la herramienta del análisis cultural - los cambios culturales que impactan en la realidad juvenil y su relación con la Pastoral Juvenil y la Pastoral Vocacional en América Latina. Vamos a estudiar el impacto de las culturas pre-moderna, moderna y pos-moderna $y$, al mismo tiempo, apuntar los factores que impactan en la Pastoral Vocacional.

La cultura es central en la vida humana y determina la visión de mundo, de la organización social, del poder político, la sexualidad, la familia, la religión, como se relacionan con los otros, los valores impor- 
tantes en la convivencia social. La cultura es la respuesta a las necesidades de cada ser humano en su búsqueda de identidad, sentido para la vida, seguridad y raíces culturales. La cultura es la experiencia acumulada de la humanidad que pasa de una generación a otra. Por eso la criatura que nace no necesita inventar todo a partir de su propia experiencia.

Los tres elementos involucrados en la transmisión de una cultura de una generación a otra son: los símbolos, los mitos y los rituales. Los tres hablan de manera especial a las emociones y buscan comunicar una cosmovisión del mundo y un sistema de valores de una generación a otra.

Creo que la evangelización de la juventud es cuestión de vida o muerte de la iglesia. Una comprensión correcta de los cambios en la sociedad puede llevarnos a anticipar situaciones y evitar errores cometidos por la iglesia en los países en desarrollo, errores que aparentemente están 1levando la iglesia a una decadencia tal vez irreversible en estos países.

Pero, antes vamos a describir algunos trazos del contexto social en el que los jóvenes latinoamericanos viven y que condicionan la manera en que las culturas moderna y posmoderna influyen en el sistema de creencia de estos jóvenes.

\section{El contexto Social de la juventud de América Latina en los últimos 20 años}

En muchos países de América Latina, en los años 80, la sustitución de dictaduras militares por gobiernos democráticos no consiguió lograr mayor justicia social. La década de los ochenta, en América Latina, fue llamada de la "década perdida" y la década de los noventas se caracterizó por el crecimiento de la miseria.

De esta manera seguía creciendo de manera preocupante la brecha entre ricos y pobres. El programa de las Naciones Unidos para el Desarrollo creó un "reloj de la pobreza" para ilustrar de manera visual la velocidad en la que la pobreza progresa en un mundo cada vez más opulento. El reloj mostraba el aumento del número de personas que vivía con menos de un dólar al día en nuestro planeta, una masa de 1,3 billones que aumentaba a la impresionante velocidad de 25 millones por año.

Con la caída del Comunismo, al comienza de los años 90, el capitalismo adquiere otro rostro que se llama capitalismo neoliberal. Con sus 
propuestas de privatización de las empresas estatales y el alejamiento del Estado del juego de libre mercado, se presenta como vencedor. Pero, la experiencia terminó con el aumento de la pobreza en América Latina. Juan Pablo II acusó al liberalismo de "subordinar la persona humana y condicionar el desarrollo de los pueblos a las fuerzas ciegas del mercado, gravando desde sus centros de poder a los países menos favorecidos con cargas insoportables." El Santo Padre considera que el neoliberalismo ha causado el "enriquecimiento exagerado de unos pocos a costa del empobrecimiento creciente de muchos, de forma que los ricos son cada vez más ricos y los pobres cada vez más pobres".

La deuda externa, la corrupción y la impunidad desviaban recursos financieros necesarios para mejorar la calidad de la educación, de la salud, de la vivienda, y para generar empleo. Los jóvenes son las mayores victimas de la mala calidad de la educación, de la salud, y de la habitación.

Como resultado la mayoría de los jóvenes en América Latina ven únicamente la perspectiva del desempleo y sueldos bajos. El desempleo es tal vez el mayor cáncer de nuestra época. Nada puede pagar el perjuicio hecho a la dignidad y a la auto-estima personal. Sin perspectivas animadoras muchos jóvenes -sobre todo de las clases populares- buscan otras salidas como son: la violencia, la drogadicción, el crimen, el suicidio. Aumenta también con ella la influencia de sectas religiosas que ofrecen salidas milagrosas.

El impacto de la pobreza y de la propaganda de consumo lleva a la desintegración del núcleo familiar, dejando fuertes cicatrices emocionales en la personalidad del joven en un momento crítico de su vida. Impresiona el número de jóvenes en las comunidades juveniles que ahora se enfrentan a problemas emocionales serios que amenazan con sacarlos del auto-control de su vida.

Al principio del nuevo milenio hay un fortalecimiento del proceso democrático y de la sociedad civil en muchos países. En el 2005, América Latina creció $5.5 \%$, con estabilidad de precios y superávit comerciales. La Argentina creció más de 10\%, Brasil 5\% y Venezuela tambiéni. Hay un aumento de esperanza en el futuro. La cuestión de fondo es si el crecimiento beneficia solamente a los más ricos o también a toda la población, de manera especial los excluidos de los beneficios del progreso. Son

i João Sayad en Folha de São Paulo, 10 Enero 2005. 
urgentes políticas que lleven a una redistribución de renta, el combate a la corrupción, la impunidad y la construcción de una democracia que no sea formal, pero sí, real. En su mensaje para el inicio del año nuevo (2005) el Papa llama la atención sobre el principio del destino universal de los bienes que "permite afrontar adecuadamente el desafío de la pobreza, teniendo en cuenta sobre todo las condiciones de miseria en que viven todavía mil millones de seres humanos".

El cambio en Uruguay, al principio de 2005, consolidó lo que se llama el nuevo consenso de izquierda en América del Sur. Tres cuartos de la región de 355 millones de habitantes hoy son gobernados por líderes de izquierda, todos surgidos en los últimos seis años para redefinir lo que la izquierda significa hoy en día. Así, los gobiernos pasarán a buscar un camino intermedio entre el capitalismo sin riendas de los años 90 y la dependencia del Estado como motor principal del desarrollo.

Ahora vamos a analizar la realidad de los jóvenes de América Latina utilizando como llave las diferentes culturas Cultura Pre-moderna, Cultura Moderna y Cultura pos-moderna. Las tres culturas influyen en el sistema de creencia de estos jóvenes. Cada una presenta aspectos importantes para la Pastoral Vocacional.

\section{Influencia de la cultura pre-moderna sobre la juventud}

En muchos lugares en América Latina la mayoría de las vocaciones de especial consagración vienen de una cultura pre-moderna (rural o medio popular en las grandes ciudades).

\section{Características de la Cultura Pre-moderna}

- La cultura tradicional mira al pasado. La manera como las cosas eran hechas en el pasado indica cómo deben hacerse hoy.

- Las mujeres, normalmente, ocupan una posición inferior a los hombres.

- Se valora más a los más viejos que a los jóvenes. Los viejos conocen mejor las tradiciones, por lo tanto son muy respetados. Los jóvenes tienen poca influencia.

- En la sociedad tradicional cada uno ocupa un lugar determinado por el nacimiento. 
- La historia es cíclica.

- La cultura tradicional es supersticiosa. No hay separación entre lo sagrado y lo profano. Una enfermedad es causada por un espíritu, un "mal de ojo", un "maleficio". Su curación depende de un ritual, de un "trabajo".

- Religión como centro. Las estructuras religiosas son usadas para integrar las personal en la sociedad civil. Además la enseñanza religiosa enfatiza las virtudes pasivas como la obediencia, la resignación, la paciencia. Las estructuras religiosas controlan, hasta cierto punto, la vida de las personas, a veces hasta sus más mínimos detalles.

- El cristianismo es una herencia. La persona automáticamente nace dentro de ella. El ambiente alrededor ayuda en su transmisión: la moralidad, las leyes civiles, las tradiciones, la opinión pública.

- Hay unidad entre lo que enseñan a los niños el párroco, el profesor, el medico, la policía.

- Los padres de familia pueden ofrecer a los niños un mensaje unificado y pueden controlar el $90 \%$ de lo que ellos experimentan.

\section{Respuesta Pastoral}

\section{a) Valorización de la religiosidad popular}

La religiosidad popular es la religión del pueblo sencillo en contraste con las personas más intelectualizados. Se manifiesta en devociones, confianza en la providencia de Dios, celebración de los misterios cristianos, los santuarios, la fiesta de los padrinos, las novenas, las promesas, los himnos, los gestos, las danzas, las peregrinaciones. La secularización pos-conciliar ayudó a purificar esta religiosidad de ciertas supersticiones y magia, insistiendo en la importancia de la actividad humana como responsable de la vida y la cultura. Hubo exceso, sin embargo. Faltaba un análisis cultural. Después del Concilio las reformas frías e intelectuales que eliminaron las novenas, las devociones y las procesiones tuvieron el efecto de cortar la lengua del pueblo, esa lengua que usaba para comunicarse con Dios. El avance de las sectas ha ayudado a la Iglesia a revalorizar la religiosidad popular.

Los jóvenes comprometidos de la pastoral encuentran dificultad para valorar la religiosidad del pueblo debido a su asimilación de los valores de la cultura moderna, como la racionalidad, el consumismo, la seculari- 
zación. Antes la religiosidad popular era vista como alienación, hoy se perciben los elementos de resistencia que dieran protección a millares de personas contra siglos de opresión. La religiosidad popular está purificada de sus elementos alienantes. Se valida su capacidad de combinar lo divino con lo humano, inteligencia y emoción. La religiosidad popular se manifiesta en el respeto por la persona, en la práctica de la fraternidad en medio de las dificultades. Esta religiosidad alimentó espiritualmente al pueblo cuando las liturgias racionales y frías aparecían como cuerpo extraño en sus vidas. Claro que la dimensión racional necesita estar también desarrollada, pero no a costas de las dimensiones emocionales e imaginativas. Los Obispos en Santo Domingo hablan de la necesidad de acompañar estas expresiones religiosas "purificándolas y abriéndolas a nuevas situaciones" para evitar el peligro del secularismo (Cf. SD 53).

El joven campesino también sufre fuerte influencia de la cultura moderna y pos-moderna a través de la TV, de la música joven y de la escuela. La religiosidad popular está siendo minada por el universo secularizado de las novelas y de la música pop que ejercen una atracción irresistible sobre los jóvenes del campo. Es importante notar que, en algunos países, campesinos e indígena son la misma cosa.

En el medio rural el proceso de cambio es más lento. Pero la mayoría de los jóvenes del medio rural se ve forzada a emigrar a la ciudad en busca de empleo y estudio. Como no están preparados para enfrentar al pluralismo cultural de la ciudad pierden el referencial religioso y se apartan de la opción de fe.

\section{b) Proceso de Concienciación}

El conocido educador Paulo Freire desarrolló una pedagogía y filosofía que llama de "Concienciación". Para él la persona humana no solamente crea cultura, sino que también es constructora de la historia. El pueblo del medio popular vive en un círculo de pobreza. Es preciso romper ese círculo. Es preciso hacer una opción por la transformación. Sin embargo, para luchar contra los problemas provocados por la pobreza y hacer la historia es necesario comprender la situación y los elementos de su cultura tradicional que la mantienen en actitud de pasividad. Nadie lucha contra algo que no comprende. Acepta con resignación. El pueblo interioriza la imagen de inferioridad que la clase dominante hace de él. Un pueblo con complejo de inferioridad no resiste; desiste. 
Para que el pueblo sea sujeto de la historia y no víctima de los elementos alienantes en su cultura, Paulo Freire propone el proceso de concientización que ayuda las personas a adquirir una conciencia crítica de las estructuras sociales, económicas y políticas que moldean sus vidas. La educación para la justicia significa involucrarse antes que hacer juegos de palabras abstractos. La acción y la teoría marchan juntas. El método compromete sacando temas generativos del contexto social de los pueblos oprimidos y analizándolos de una manera crítica -en pequeños grupos y comunidades. El proceso de conscientizacion quita el velo a los factores culturales que condicionan a los grupos marginados a aceptar pasivamente su situación y animarles a asumir control de sus vidas. Este proceso de conscientizacion despierta la conciencia de las personas para que sean sujeto de su propio destino y puedan construir la historia. Esta nueva misión y realización que tienen un papel en la construcción de la humanidad despierta entusiasmo y compromiso. Se desmonta esa visión mágica de la realidad en la que son víctimas pasivas frente fuerzas ciegas. La motivación y el compromiso tienen raíces más profundas cuando el proceso educacional conecta esta conciencia con una visión de fe. Las personal que ahora ven -más tarde- nunca dejarán de ver.

Cuando la cultura tradicional es trabajada, tanto en la ciudad como en el campo, en una perspectiva de transformación, purificándola de los elementos alienantes (conformismo, visión mágica del proceso político...), puede volverse cultura popular. Al confrontarlo con la cultura moderna es necesario crear un filtro que elimine aspectos negativos de la modernidad y deje pasar los aspectos positivos.

\section{c) Trabajo Político y Trabajo Cultural}

La búsqueda de transformaciones estructurales es precaria, si no está acompañada también por un trabajo cultural. Durante varios años, un cura hizo un trabajo de evangelización que unía fe y política en una diócesis del noreste de Brasil. En las elecciones, el pueblo eligió diputados conservadores apoyados y financiados por los grandes latifundistas y grupos económicos de la región. El cura se irritó. Las personas vivían reclamándole por la situación de pobreza y, ahora, cuando aparecía la oportunidad de cambiar la situación, votan por candidatos que iban a trabajar contra sus intereses. 
El cura no se daba cuenta de que se trataba de una cuestión cultural. El pueblo recibía favores de los grandes que los explotaban. En época de elecciones los políticos conservadores "compraban" los votos (canastas básicas, ropa, remedios). Para ese pueblo había un dato cultural fuerte: quien recibe un favor está obligado a pagarlo más tarde. No podían votar contra aquel que les había hecho un favor. Para cambiar ese dato cultural necesitaban antes entenderlo, para después hacer un trabajo de concientización. El análisis político no podía estar separado del análisis cultural.

\section{d) Sin Valorización de las Culturas Tradicionales no hay Transfor- mación}

La cultura tradicional de un pueblo es importante. Su identidad y raíces están ahí. Toda transformación pasa por la valorización de esa cultura. En este siglo muchos países que conquistaron su independencia contra el colonialismo, comenzaron trabajando la cultura del pueblo, la lengua, las danzas, las costumbres, la literatura, las tradiciones, los símbolos, los mitos y los rituales. Solamente un pueblo con raíces puede tener identidad y sentirse orgulloso como pueblo. El trabajo cultural aleja el sentimiento de inferioridad ante otros pueblos. Ejemplo: Los jóvenes hispanos en Estados Unidos.

Al mismo tiempo, debe evitarse la idealización. La cultura tradicional contiene muchos elementos opresores y autoritarios que necesitan ser purificados.

\section{Influencia de la modernidad sobre la juventud}

Paralelamente, en los años 80 hubo una fuerte influencia de la cultura moderna influyendo sobre la manera de pensar y de comportarse de la juventud latinoamericana. Esta influencia continúa. Igualmente los jóvenes de familias de cultura premoderna (del medio rural o de los barrios populares de las ciudades) se sienten fascinados por la cultura nueva y quieren abrazarla. Esta cultura se propaga por los medios de comunicación y no necesita de un proceso de industrialización para penetrar' ${ }^{1}$ El

${ }^{1}$ Nestor Garía Canclini. Examine el malentendido presente sobre todo en textos de 
proceso de urbanización en América Latina acentúa la penetración de esta nueva mentalidad. La situación brasileña, por ejemplo, refleja la misma tendencia que los demás países del continente. "La población urbana que no llegaba al 35\% del total en 1950, está hoy próxima al 75\%"2. Un millón y medio de personas emigran del campo a la ciudad cada año. La importancia de esta realidad es captada por el documento de Santo Domingo. Aquí nos concentramos en los valores positivos de la modernidad. Claro, como toda cultura, hay también valores negativos, como, por ejemplo, el individualismo y materialismo, que debemos cuestionar.

Hay un cambio importante en la cosmovisión del mundo que impacta la manera de encarar la fe y la Iglesia. Cuando la cultura tradicional se encuentra con la cultura moderna las personas dan el paso de una actitud fatalista a una actitud de elección. Los años 80 marcan un paso de salida desde una cultura influenciada por siglos de cristiandad hacia una cultura dominada por la razón, la tecnología y el dinero. Los valores importantes de la Cultura moderna que ejercerán fuerte influencia sobre la juventud latinoamericana son: la democracia, el dialogo, la búsqueda de felicidad humana, transparencia, derechos individuales, libertad, sexualidad, igualdad de las mujeres. La conciencia de autonomía humana y la secularización son valores importantes.

Una religión que exige sumisión y quiere controlar la vida de las personas en sus mínimos detalles, encuentra poca receptividad en este nuevo contexto cultural. Los jóvenes vibran con estos valores y rechazan un modelo de iglesia que niega en su práctica estos valores. El surgimiento de la democracia tiene sus reflejos dentro de la propia Iglesia. Toda auto-

sociólogos y políticos que cuestiona la necesidad de preocuparse con las culturas modernas y posmodernas ya que en América latina no tuvimos una industrialización sólida, una gran parte de la población es analfabeta, las oligarquías precapitalistas todavía controlan muchas áreas rurales y la política frecuentemente se basa en el clientelismo. En muchas áreas las estructuras políticas y económicas son premodernas. Estas culturas llegan independiente de estos factores. Llegan a través de grandes complejos empresariales que controlan los medios de comunicación de masa: canales de televisión, emisoras de radio, prensa, revistas, propaganda, discos, cassettes, videos y computadoras. Los medios electrónicos de comunicación no exigen que sepa leer y escribir para recibir y entender su mensaje". La velocidad de los cambios tecnológicos distingue nuestra sociedad de todas las sociedades anteriores. El autor concluye: "Al llegar a la década de los 90's, es innegable que América Latina sí se ha modernizado".

2 Directrizes Gerais da Acão Pastoral da Igreja no Brasil (1991-1994) - CNBB, Ed. Paulinas, São Paulo, 1991, p. 66. 
ridad, en la sociedad moderna, es desmitificada por los medios de comunicación: presidentes, gobernadores, políticos, sacerdotes, obispos. Solamente los fundamentalistas se someten con obediencia ciega. Los jóvenes tienen anticuerpos que reaccionan contra cualquier cosa que sea impuesta desde arriba, por los padres, profesores, sacerdotes u obispos. "Los signos de los tiempos influyen en el proceso de consulta y toma de decisiones en la Iglesia... Un autoritarismo que fue aceptado en el pasado está fuera de moda hoy. Una transparencia que no se esperaba en el pasado es exigida por la sociedad de hoy"3. La autoridad de los líderes de la Iglesia, en el futuro, parece depender más de su peso moral y estilo de vida que de presupuestos dogmáticos. El Vaticano II acoge los valores positivos de esta nuevo visión del mundo cuando afirma que "Es solamente dentro de la libertad que la persona humana se puede dirigir a Dios" (GS).

Un elemento que tiene mucho que ver con la Pastoral Vocacional es el tema de Secularismo. El secularismo es diferente de la secularización. El secularismo niega la existencia de Dios y cree que solo la ciencia puede explicar el significado de la vida. El secularismo tiene una penetración de modo especial en los medios universitarios, los futuros formadores de la opinión pública. Los grandes pensadores que contribuyeron al nacimiento de la modernidad estaban contra la religión y Dios. Freud decía que Dios era una invención del inconsciente para personas débiles y sin capacidad de ser el sujeto de su vida. Nietzsche inventó la frase "Dios está muerto". Marx afirmaba que "la religión es el opio del pueblo". Es importante recordar que un buen número de líderes en pastoral juvenil son universitarios o estudiantes que se están preparando para ingresar en la universidad. Muchos de estos son jóvenes de origen popular que consiguieron llegar a la universidad por ser muy inteligentes y trabajadores. Una joven me contó: "En la universidad cuando los otros estudiantes descubrieron que era cristiana practicante, se burlaron de mí. En la universidad los jóvenes tienen contacto con profesores y libros que afirman que la Iglesia a lo largo de la historia ha sido una fuerza contra el progreso y ha apoyado a las clases dominantes contra los movimientos de liberación. Muchos de estos jóvenes encontraron un espacio dentro de la Iglesia de América Latina en donde fue posible profundizar una base intelectual para la fe y tuvieron conciencia de que no bastaba una fe ciega. La teología de

\footnotetext{
${ }^{3}$ Monsignor Laurence Ryan, Revista Furrow, agosto 87, Dublin.
} 
la liberación que nació en América latina fue importante para mostrar que la religión puede ser una herramienta de liberación o también transformarla en una ideología de opresión.

Es importante distinguir entre la secularización y el secularismo. La secularización, por otro lado, es algo positivo. No combate la religión pero exige que sea respetada la autonomía de la ciencia. La secularización es el paso de una cultura "sagrada" a una cultura "profana". La secularización es el reconocimiento de la autonomía de la ciencia delante de la religión. Se trata de algo positivo. No le compete a la Iglesia decidir si los descubrimientos de los científicos como Galileo son ciertos o no. El Vaticano II reconoce que "por una vinculación excesivamente estrecha entre la actividad humana y la religión, se ha menospreciado la autonomía del hombre, de la sociedad o de la ciencia" (GS 36). Las cosas creadas por Dios (la naturaleza) y las creadas por el hombre (la ciencia y las organizaciones sociales), tienen sus propias leyes y valores, no están en contradicción. Así la secularización vino a ayudar a purificar aspectos negativos de la religión, como la superstición, el fatalismo, la alienación, el fundamentalismo. Para un joven estudiante, una religión purificada de esta manera, tiene más credibilidad. Por otro lado, una secularización equilibrada reconoce la incapacidad de las ciencias para dar respuestas a situaciones límites: la muerte, el sentido de la vida y los muchos dramas personales.

La Pastoral Vocacional está conectada con la capacidad del joven de encontrar una base intelectual para su fe, una base intelectual que integre los valores positivos de la modernidad.

\section{El trabajo pastoral con jóvenes en este contexto}

En la década de los 80's la Iglesia, en muchos lugares, supo acoger muchos de éstos valores positivos de la modernidad en su trabajo pastoral con la juventud. A diferencia de la Iglesia de Europa el secularismo no tuvo la misma penetración en el medio de la juventud latinoamericana y por lo tanto no afectó la creencia juvenil de la misma manera. A través de la Pastoral Juvenil y la pastoral de conjunto se abren espacios en los que los jóvenes son protagonistas y participan de las decisiones. Junto con los otros jóvenes de la sociedad civil los jóvenes católicos se comprometieron en la promoción de la democracia, libertad, justicia, igualdad y derechos humanos. Fue un tiempo de ideales colectivos, de creer que era posi- 
ble construir la patria grande en la que no se daría más la exclusión de los beneficios del progreso de grandes sectores de la población. Fueron protagonistas en el esfuerzo para sustituir gobiernos militares por gobiernos democráticamente elegidos.

Las utopías colectivas que apuntaban a una nueva sociedad ejercían gran atracción sobre los jóvenes. Fue un tiempo de poner en practica las conclusiones de Vaticano II, Medellín y Puebla. Fue una época en que los jóvenes se entusiasmaron con el reto de construir una Iglesia de comunión y participación que tendría credibilidad y que podría dialogar con el mundo moderno. Fue un tiempo en que el se invertía mucho en el trabajo pastoral con jóvenes, en la formación de comunidades y grupos juveniles y de la formación de una red de estos grupos a nivel diocesano, nacional y latinoamericano. Los jóvenes abrazaron con entusiasmo las dos prioridades de Puebla: los jóvenes y los pobres. Se formó una generación de líderes. Surgieran muchas vocaciones para la vida religiosa y para la participación de los laicos en la transformación de la sociedad. La dimensión intelectual de la fe era importante. Fue un tiempo de grandes debates, de una generación de jóvenes que leían y estudiaban mucho. Muchos de los líderes formados en aquel tiempo continúan comprometidos hasta hoy.

Hubo un fortalecimiento de la organización de la Pastoral Juvenil Latinoamericana. En 1984 se organizó un Encuentro Latino Americano de Responsables Nacionales de Pastoral Juvenil, convocado por la Sección de Juventud del CELAM (Consejo Episcopal Latinoamericano), con la participación de 14 países. En este Encuentro, se inició un proceso para aclarar el proyecto de PJ a nivel del continente. En los años siguientes hubo encuentros anuales con la participación de casi la totalidad de 22 países. El nuevo modelo se afirmó rápidamente, a partir de asambleas diocesanas y nacionales. En muchos países, se inició la experiencia de una pastoral coordinada por los propios jóvenes, y asesorada por adultos -semejante a la experiencia de la Acción Católica Especializada-, en los años 60 y también la formación de asesores para acompañar este proceso. Ésta fue el principio de una de las experiencias pastorales más significativas del continente.

El entusiasmo generado llevó a los jóvenes y a los asesores a empeñarse en la organización de estructuras de coordinación y de acompañamiento en diferentes niveles: región, diócesis, sector, parroquia. A finales de la década de los 80 se consiguió un "milagro". A pesar de la diversidad 
de experiencias pastorales y de diferencias culturales, los documentos revelaron un consenso continental sobre las grandes líneas y metodologías de la Pastoral Juvenil. Algunos países están más adelantados, otros, aún están empezando el camino, pero todos están de acuerdo sobre el punto de llegada.

La Pastoral Juvenil es la pastoral que más creció dentro del CELAM, en los 80 , en términos de estructuras de participación democráticas, claridad de objetivos y encarnación en la realidad latinoamericana. Las muchas tensiones que surgieron en el proceso fueron superadas mediante la conducción inteligente y evangélica del proceso. Uno de los puntos culminantes de este caminar fue el Primer Congreso Latinoamericano de Jóvenes, realizado en Cochabamba en 1991 con la presencia de 2 mil delegados de 19 países.

El rechazo de la Iglesia fue menos acentuado en América que en los países de Europa porque la Iglesia supo dar respuestas a los grandes desafíos del continente. En muchos lugares la Iglesia ejercía su rol profético y fue la voz de los sin voz.

\section{Influencia de la pos-modernidad}

La fecha de 1989, con la caída del Muro de Berlín y del Comunismo, es considerada fecha simbólica del surgimiento más fuerte de la nueva cultura posmoderna que ejerce una influencia dramática sobre el cambio de mentalidad de la juventud latinoamericana. Debido a la globalización y al poder de comunicación de los medios electrónicos este cambio se sintió fuertemente también en el medio de la juventud latinoamericana.

Queremos resaltar algunos elementos de esta nueva cultura que influyen en el proceso de evangelización de los jóvenes y en el fenómeno de increencia juvenil:

a) La subjetividad es un valor central.

b) La vuelta de lo sagrado.

c) La centralidad de las emociones y de lo no-racional.

a) Subjetividad, valor central

La tendencia a la subjetividad se acentúa cada vez más. La generación de jóvenes de los años 80 que acogía el ideal colectivo de construir 
un mundo mejor, es ahora reemplazada por una generación preocupada por la subjetividad, por sus necesidades personales, por sus sentimientos, por el mejoramiento de su autoestima, por su confianza, por la liberación de los traumas etc. Ahora se percibe "una nueva generación de jóvenes definitivamente desligada de las identidades de los años 60 y 70, pero con enorme dificultad para definir su identidad y su lugar en la historia y en la sociedad"4. El sueño colectivo de un mundo mejor que electrificaba a los jóvenes en todo mundo, en los años sesenta, fue sustituido por el deseo de retirarse a su propio mundo particular y limitar sus horizontes a problemas y ambiciones personales. Se trata de una generación sin continuidad con las generaciones anteriores, una generación que no se interesa por las luchas y los sueños de sus padres. La caída de las ideologías hace que muchos jóvenes ya no se proyecten hacia el futuro. Este fenómeno tiene el efecto de forzarlos a concentrarse, en el momento actual, en la búsqueda de sensaciones y emociones pasajeras, lo que no les conduce a un sentido más profundo en la vida. Al mismo tiempo, las personas están exhaustas por la sensación de caos, la falta de soluciones para los probleInas sociales y la aparente invencibilidad del poder de los grupos de intereses, de las personas ricas que dictan las reglas del juego. "Hay síntomas claros de una apatía o cansancio generalizado en la juventud y de su proyección en las organizaciones sociales como resultado de la desilusión política y la falta de crédito en la transformación de las estructuras. Es notable la tendencia a lo privado y, también, la búsqueda de sentido, con una fuerte inclinación pragmática, desinstitucionalizada, desideologizada: estos jóvenes no pretenden cambiar la sociedad por dentro, como en los años sesenta, sino que optan por vivir al margen de ella"5.

Las relaciones personales son importantes. La participación del joven en una organización o institución como, por ejemplo, la escuela, un grupo juvenil, está fuertemente motivada por la búsqueda de establecer relaciones con otros jóvenes. Una pastoral, que no da importancia ni crea condiciones para facilitar la profundización de las relaciones humanas, pierde a los jóvenes.

4 Viviendo la Esperanza en Tiempos de Búsqueda, IX Comité Latinoamericano MIEC Pax Romana-JECI-1 al 12 de julio de 1991, Vitoria Gasteiz, España.

${ }^{5}$ De Pablo, Valentín, (1985). Juventud, Iglesia y Comunidad, CCS: Madrid. 
En mi experiencia la juventud es tan idealista y generosa como antes. Basta saber trabajar con ella, motivarla, horadar la armadura del individualismo que mantiene sofocado este núcleo de energía divina que está dentro de cada ser humano y lo lleva a salir de sí e ir al encuentro del otro con los brazos extendidos. La cuestión es la metodología de trabajo y la paciencia para acompañar los procesos de educación en la fe que llevan más tiempo.

Hay un cambio de las estructuras marco en la sociedad para los problemas cotidianos. Cómo se siente tiene mucho que ver con los compromisos asumidos. Hay necesidad de mantener equilibrio entre el proyecto individual y el proyecto colectivo. Un conocido autor americano, Steinem, plantea el desafío de esta manera: "Es como si los dos grandes movimientos de nuestro tiempo, el movimiento por la justicia social y el movimiento por la autorrealización, fuesen dos mitades de un todo esperando juntarse en grupos realmente revolucionarios"6.

\section{b) La vuelta de lo sagrado}

En esta nueva coyuntura hay una vuelta a la religión. Las conclusiones de una investigación ${ }^{7}$ hecha entre los jóvenes brasileños refuerza este dato: el 98\% de los 800 brasileños encuestados en edades comprendidas entre 15 y 24 años dijeron creer en Dios.

Se trata, no obstante, de una religión más privada, sin preocupación por las necesidades de los otros. No está de moda defender a los pobres y grupos marginados y decir que ellos también tienen derecho a disponer de las mismas oportunidades.

En el contexto de la modernidad se hablaba de la "muerte de Dios". En los años 60 y 70, eran frecuentes, entre los jóvenes de América Latina, las actitudes anticlericales y anti-religiosas. En el nuevo contexto de la cultura posmoderna hay una sorprendente apertura hacia lo trascendente y lo sagrado.

La crisis de valores provocada por el secularismo ha originado una vuelta a la religión. Hoy hasta la ciencia está creando una conciencia de que el misterio y la trascendencia son realidades profundas de la vida

\footnotetext{
${ }^{6}$ Steinem, G. (1993). Revolution from within. Boston: Little, Brown.

7 Investigación Revista VEJA, Agosto 2003.
} 
humana. Estudios en diferentes países muestran que hay una reactivación

mundial de la religión, especialmente en los países en desarrollo. La gran mayoría de los jóvenes creen en Dios. Es como si las personas hubieran cargado con un vacío que necesitaba de Dios e intentaban llenar con otras cosas. Ahora toman conciencia de que el juego no funciona. Las personas que se ven obligadas a afrentar la tarea de criar a los hijos en un mundo confuso sienten la necesidad de un ancla. Se trata de un fenómeno nuevo que está cambiando los pronósticos que llevarían a un declive inevitable de la creencia religiosa en la época moderna. Todos pensaban que el secularismo continuaba socavando la religión, y que nada podía impedirlo" concluye David Barret, editor de World Christian Encyclopedia. "Hemos comprobado que todos estábamos equivocados".

Frente al miedo, la prisa y el caos, muchas personas vuelven a manifestaciones pseudo-religiosas (ocultismo, horóscopos, astrología...). Otras se refugian en sectas fundamentalistas donde las verdades son enseñadas de manera dogmática y la angustia de la duda queda lejos. En este último caso el costo es alto: fanatismo y eliminación del contenido de la fe. Está claro para muchos intelectuales, hoy, que el impulso religioso es más que una invención del subconsciente.

Un sector de la juventud busca una nueva calidad de vida. La actitud antirreligiosa de los años sesenta y setenta dará lugar a un nuevo despertar religioso. Las necesidades más profundas no están encontrando respuesta en un ambiente materialista y secularizado. La incapacidad de la ciencia para resolver muchos de los problemas humanos se ve clara ahora. Hay necesidad de ir más al fondo. Se siente la falta de una paz espiritual que ayude a tomar la vida en sus propias manos. Hay búsqueda de una experiencia religiosa que dé significado a la vida y devuelva la alegría de vivir. Muchos jóvenes están en crisis porque les falta una fe concreta, de vida, no sólo de palabras. Hay una búsqueda de espiritualidad que dé unidad a la vida y ayude a concentrarse sobre sí mismo - con su centro. Antes de afrontar una difícil tarea o de tomar una decisión importante es frecuente concentrar el espíritu. Se trata del inicio de la búsqueda de una espiritualidad más profunda.

\section{Rechazo de la religión organizada}

Aunque este cambio cultural puede ofrecer una tierra fértil para la religión, debemos analizar con cautela la vuelta a lo sagrado. La apertura 
hacia lo trascendente no significa necesariamente una aceptación de la religión organizada o de la Iglesia. Mucho del fermento espiritual del momento está aconteciendo fuera de la religión organizada. Algunos estudios han demostrados que muchos jóvenes están buscando razones para vivir sin involucrarse con una iglesia ${ }^{8}$. Hay una búsqueda de espiritualidad en grupos y personas no conectados con la religión organizada o institucionalizada. Un ejemplo son los adeptos a la espiritualidad New age. Estamos hablando del despertar religioso de una generación que afrenta la tarea de llevar la vida cotidiana, compleja y contradictoria y sin puntos de referencia seguros. Se trata de una espiritualidad más limitada y superficial, una espiritualidad de supermercado donde va sacando de los estantes lo que conviene y combina con sus propias conveniencias. Se trata de una vuelta a una religión privada, sin preocupación por las necesidades de los otros. No está de moda en este nuevo espíritu religioso defender a los pobres y a grupos marginados y decir que ellos también tienen derecho a las mismas oportunidades.

Pero, el cambio cultural abre una puerta de entrada para el proceso de evangelización de los jóvenes. Es más fácil trabajar la espiritualidad que en los años 80 cuando el tiempo dedicado a la espiritualidad y a las celebraciones fue visto con frecuencia como una pérdida de tiempo ante la urgencia de la transformación social.

Es necesario resistir la tentación de diluir el mensaje del Evangelio. El pueblo de Dios necesita recibir todo el mensaje del Evangelio y no un mensaje recortado que abandona al individuo a sus propios caprichos y conveniencias.

\section{c) La centralidad de las emociones y el no-racional}

Hay una tendencia fuerte en los pensadores posmodernos a criticar la glorificación de la razón, característica central de la cultura moderna. En su origen, la cultura moderna estuvo fuertemente influenciada por un grupo de intelectualistas (llamados iluministas) que argumentaban que los factores no-racionales eran los causantes de la miseria y de la pobreza y

8 Tonelli, Ricardo, Pastoral Juvenil, Anunciar la Fe en Jesus Cristo en la Vida Diária [Youth ministry, proclaiming the faith in Jesus Christ in daily life], Madrid: CCS, P. 50. 
que el progreso de la humanidad dependía de la capacidad del raciocinio humano, de descubrir las verdades universales capaces de construir un mundo nuevo. Pero hay otro lado. Hoy en día se percibe que la apelación a una "verdad" universal puede ser una máscara para defender intereses de grupos dominantes, de poder, de valores diferentes. Tampoco se puede ignorar el lado negativo de la persona humana, la presencia de fuerzas irracionales, la ganancia, el deseo de poder, y la decepción que pueden causar daños enormes a las relaciones humanas.

El lado positivo es la reacción contra el dogmatismo del pasado. Los análisis simplistas, tanto de la izquierda como de la derecha, que veían las situaciones en blanco y negro no captaban su complejidad e impedían el progreso.

La tendencia de la modernidad a aceptar solamente lo que se puede comprobar e ignorar el hecho de que lo que tiene más valor frecuentemente hinca sus raíces en factores que no pueden ser comprobados: la cultura, los mitos, las costumbres, las tradiciones, la religión. Las personas tienen necesidades más profundas que no encuentran respuesta solamente en la razón y la ciencia. Vivimos dentro de una red de relaciones que determinan la felicidad, la auto-realización, y la identidad. No dependen sólo del poder de la razón. Hay una irrupción volcánica de estas necesidades en toda parte.

Una glorificación excesiva de la razón sacrifica otras dimensiones de la persona humana. La idea de que la razón por sí misma podía resolver todos los problemas humanos ha sido desmentida por los resultados: guerras, aumento de la pobreza, de la criminalidad, de los problemas psicológicos. La felicidad y el progreso no dependen solamente de la razón y la ciencia; las personas existen dentro de una red de relaciones que pueden ayudarlas o aplastarlas, que determinan la identidad, la felicidad y la autorrealización. Ninguna persona es una isla.

El fenómeno que más llama la atención dentro de este nuevo contexto cultural es el crecimiento del neo-pentecostalismo que acentúa la subjetividad y el elemento afectivo en su metodología de evangelización. Las periferias de las grandes ciudades están llenas de iglesias pentecostales en lugares donde no hay ninguna iglesia católica. En su libro "Changing Tides" Samuel Escobar cita al Padre Franz Damen, secretario de la Conferencia de los Obispos de Bolivia: "Según las estadísticas cada hora 400 católicos se afilian a una secta protestante". 
La evolución de la situación religiosa en Brasil refleja lo que está sucediendo en los demás países de América Latina:

- Según una investigación hecha en las grandes capitales el 67\% de las personas se declaran católicos (aunque la mayoría no son practicantes).

- Una investigación realizada por los evangélicos en 1992 proyectaba que para el año 2000 iban a tener 22 millones de miembros en Brasil, es decir el $15 \%$ de la población.

- A principios de siglo:

- El 99\% de los brasileños eran católicos;

- El 4,7\% se declararon sin religión.

- En el ultimo censo:

- El 73\% de los brasileños son católicos;

- El 7,4\% se declararon sin religión (más de 12 millones. La gran mayoría hombres, adolescentes y jóvenes, residentes en la ciudad).

- En 1970 eran 91,8\% de católicos

- En 1991 eran 83,3\% de católicos

- En 2000 eran 73,9\% de católicos

Observación: Entre 1991 y 2000 el número de católicos disminuyó en un 10\% Se prevé que en el próximo censo el total de los católicos será el $65 \%$.

Las causas son numerosas y complejas. Algunas de estas causas son los cambios culturales (modernización, secularización, individualización, subjetivismo, relativismo, hedonismo). Estos cambios afectan a todas las religiones, pero la capacidad de resistirlos o de aprovecharlos es muy diferente de una religión a otra. La expansión de una religión está relacionada con su dinamismo, su capacidad de movilización y su estrategia de evangelización.

Dentro del contexto de la posmodernidad el pentecostalismo ejerce cierta atracción: está basado en la experiencia afectiva y personal. Cualquier persona puede hablar en lenguas, predicar y tener acceso directo a Dios, sin mediaciones, El pentecostalismo ejerce atracción sobre los pobres y analfabetos especialmente en países en los que el clero, muy estudiado, controla lo sagrado. La experiencia de Dios es considerada más importante que el dogma. Así es como las personas se sienten seguras en medio del caos constante del mundo posmoderno que les rodea. Según una investigación hecha en Brasil los miembros de las iglesias pentecostales son más pobres y con bajo nivel de escolaridad y hay pocos jóvenes, 
"Las iglesias pentecostales, en su conjunto, son más urbanas que rurales, y más mujeres que hombres (hay casi un 10\% más de mujeres), tiene muchos niños (hasta los 15 años), pero pocos adolescentes de 15-20 años y, en general, en todas las edades, están un poco debajo de la promedia. En cuanto a la raza o color, tienen más negros, mestizos e indígenas de media; tienen poco amarillos. El nivel de escolaridad es bajo. Casi no hay fieles con formación superior o postgrado... ${ }^{9}$ Llama la atención el hecho de que las sectas, pese a su éxito en crecimiento numérico, tienen dificultad para involucrar a los jóvenes.

En la Iglesia Católica el Movimiento de Renovación Carismático que sigue la línea del neopentecostalismo, es el movimiento apostólico que más crece. Muchas vocaciones religiosas que antes nacía en la Pastoral Juvenil ahora son despertadas por el movimiento. En muchos países su crecimiento se fortalece por el control de emisoras de TV y radio.

\section{El trabajo pastoral con jóvenes en este nuevo contexto}

La tendencia a acentuar el no-racionalismo, dentro de la cultura posmoderna, tiene fuerte penetración en el medio de la juventud y presenta cuestiones importantes referentes a la metodología de trabajo pastoral y la increencia juvenil. La razón debe dejar espacio a las emociones, la imaginación y la fe. El mensaje del Evangelio debe presentarse con respuestas a todas las dimensiones de la vida del joven. La formación debe ser integral. Es necesario restablecer la armonía entre la persona y la razón, las emociones, la imaginación, la divinidad, con los otros y con la naturaleza.

Cierta absolutización de la dimensión racional en el pasado ha alejado a muchos jóvenes de la pastoral juvenil. Hizo falta una conciencia antropológica del papel de los símbolos, del mito, del ritual. ¿Cómo tra-

${ }^{9}$ Basándose en el Censo 2000, Leonildo Silveira Campos constató que el 4,94\% de los brasileños tiene 15 ó más años de estudios; los católicos tienen el mismo porcentaje; los evangélicos tradicionales llegan a un 6,42 , los espiritistas al $; 21,11 \%$ ! Por debajo de la media están los no creyentes $(4,66 \%)$ y, claramente, los pentecostales $(1,55 \%)$.

En el Censo 2000, sorprende también el crecimiento de los "no creyentes", que se convierten -tras los católicos y evangélicos- en el tercer grupo más numeroso, con casi 12,5 millones $(7,4 \%$ de la población).

Esta categoría es poco conocida y poco estudiada. Pero los datos del Censo revelan algo al respecto. Se trata de un grupo (hay "no creyentes" también en las clases altas) 
bajar la subjetividad, como puerta de entrada para el mensaje religioso? Hoy en día, un trabajo pastoral basado únicamente en una metodología racional, es una receta para el fracaso.

\section{El peligro de la absolutización de las emociones}

Por otra parte, no podemos reducir nuestra estrategia pastoral a los sentimientos. Es necesario mantener un equilibrio entre los dos polos: el racional y el emocional. Emociones, sentimientos e imaginación necesitan ser integrados en una metodología racional. La absolutización de las emociones lleva al desvanecimiento de lo intelectual, del compromiso transformador y de la conciencia crítica. Lleva a la superficialidad y a la falta de perseverancia. Hay una distorsión de la fe. La fe depende de sentir emociones. Mas las emociones son pasajeras. Cuando desaparecen las emociones también desaparece la fe. La verdadera fe es purificada por la cruz, la ausencia de emociones, la "noche oscura del alma".

La absolutización de las emociones fácilmente lleva al fundamentalismo ${ }^{10}$ que es un desafío hoy dentro del Islam, del Protestantismo, del Judaísmo y también dentro del Catolicismo.

También la absolutización de las emociones quita las teorías globales, las utopías y valores universales. Quita base para una crítica social y la formación de la conciencia crítica de los jóvenes. Las estructuras sociales, políticas y económicas injustas que causan la pobreza y marginalización de grandes sectores de la población desaparecen de los debates. Pero, por esto, no deja de existir. Continúa como tarea urgente la necesidad de cambiar las reglas de organización social que favorece una situación en la que hay "ricos cada vez más ricos a costa de pobres cada vez más pobres". Jamás la opción evangélica por los empobrecidos ha sido tan importante. En este momento de encrucijada de la historia, hay necesidad de resistir-

${ }^{10} \mathrm{El} \mathrm{fundamentalismo} \mathrm{es} \mathrm{un} \mathrm{fenómeno} \mathrm{que} \mathrm{acontece} \mathrm{cuando} \mathrm{hay} \mathrm{un} \mathrm{cambio} \mathrm{cultural} \mathrm{rápi-}$ do. Los fundamentalistas analizan los acontecimientos y situaciones a partir de una óptica emocional más que racional. Son anti-intelectuales e intolerantes con las personas que no concuerdan con ellos. Son también sectarios, porque les falta la visión global de la vida. En tiempos de inseguridad esas personas necesitan líderes fuertes --salvadores- que den respuestas rápidas no necesitando enfrentar la agonía de duda e inseguridad. Procuran una estabilidad que les de sensación de seguridad, pues no todos consiguen convivir con la libertad. El fundamentalismo religioso dificulta el trabajo ecuménico de promover mayor unión entre las iglesias cristianas. hoy, el fundamentalismo es un movimiento mundial tanto dentro de la religión como dentro de la política. 
se a la tentación de abandonar la dimensión profética de la fe para huir hacia una fe privada.

Los horizontes de una gran parte de la nueva generación no se proyectan hacia el futuro. La preocupación está en el presente, el bienestar, las sensaciones del momento. La actitud es: "cuando llegue el futuro, veremos. La tendencia en el mundo posmoderno a absolutizar la subjetividad provoca también la tendencia a absolutizar el placer. Como resultado, falta a muchos jóvenes un cuadro de valores que sean referencia para dar una dirección a su vida. No hay valores universales; son subjetivos. La actitud de muchos jóvenes es "Hago lo que me da la gana". Siento que éste es criterio de lo que es cierto o equivocado. Se ignoran las exigencias de la solidaridad y del amor. El significado en la vida se torna más superficial. Se trata de una cultura del placer. No se distingue lo cierto del error, entre el bien y el mal.

\section{El desafio de una nueva síntesis}

Existe el desafío de una nueva síntesis - racional/emocional para enfrentar al fenómeno de la increencia juvenil. La frase de Descarte, "Pienso, luego existo" es hoy sustituida por otra frase "Siento, luego existo". Es necesario encontrar una nueva síntesis que integre la dimensión racional con las otras dimensiones de la vida del joven. Descubrir nuevos métodos y formas de anunciar el evangelio de modo dinámico y vivo para todos los que buscan una transcendencia o sentido de la vida. Acogemos el espíritu de una nueva época, pero también somos críticos con sus limitaciones.

Por un lado, los movimientos apostólicos que acentúan la dimensión emocional necesitan también, trabajar la dimensión intelectual y profética de la fe. Por otro lado, la pastoral juvenil necesita trabajar la subjetividad y los sentimientos como puerta de entrada para el mensaje religioso. Las celebraciones necesitan ser más innovadoras; menos racionales. Se busca vincular los elementos afro de la cultura popular: los instrumentos musicales, el uso del cuerpo, la danza, el espacio celebrativo. En los últimos años he hecho experiencia con un curso que busca hacer esta síntesis y que sirve como herramienta para fortalecer la pastoral orgánica.

La comprensión de la cultura moderna nos ayuda a entender la importancia de nuevas respuestas para nuevos problemas. La repetición 
de métodos tradicionales no es suficiente para afrentar los retos de un mundo nuevo-increíblemente diferente que existió en el pasado. Los valores y la mente de los jóvenes son moldeados por las culturas moderna y posmoderna.

\section{Queda una pregunta importante: ¿Será que nuestro destino es el mismo de la Iglesia de Europa?}

En casi todos los países de Europa, cada vez más, las personas mantienen pocos vínculos con la Iglesia. Buscan la Iglesia para los momentos más intensos de la vida humana, como, por ejemplo, el bautismo, el casamiento, la muerte. La actitud es: por si Dios existe, no quiero ser su enemigo, por lo tanto voy a mantener algunos vínculos con la religión organizada. Gabriel García Márquez resume esta actitud: "No creo en Dios, pero tengo miedo de Él". El ateísmo práctico es un desafío mucho más peligroso para la fe de los jóvenes que el ateísmo formal. El ateísmo práctico es el enemigo que amenaza el futuro de la fe de los jóvenes.

Pienso que el aumento de la increencia juvenil en los países desarrollados, de manera especial en Europa, puede iluminar cuáles serán los caminos del futuro en América Latina. Podemos aprender de lo que está aconteciendo en los países desarrollados, anticipar los cambios culturales que afectan a la increencia juvenil y evitar los errores cometidos.

Nos encontramos con problema de la disminución alarmante de las vocaciones religiosas. También, los jóvenes, en general, están abandonando la Iglesia en número considerable. Son pocos los jóvenes que participan de la misa dominical. Cierto: no podemos reducir el Cristianismo al ritual y frecuencia de las celebraciones. Por otro lado no podemos ignorar su importancia. La participación en la celebración litúrgica desempeña un papel importante en la vida de los cristianos. Es un momento privilegiado para hacer explicita la fe, de encuentro con otras personas y de compartir la vida. La opción de no asistir a la misa, está frecuentemente acompañada por el abandono de otros aspectos visibles de la fe. Para los jóvenes el abandono de la Iglesia puede significar también el de un marco de referencia espiritual y ético.

Los peritos dan cuenta hoy de que son suficientes sólo dos generaciones para que las personas pierdan todo contacto con el cristianismo. Si 
la primera generación no practica la religión y no educa a los hijos en la fe, la segunda no tendrá ninguna referencia de fe cristiana. Algunos pueden volver por motivos culturales para participar en una boda o misa.

En las parroquias de las ciudades grandes de América Latina llama la atención la ausencia de jóvenes en la misa parroquial. En algunos barrios de clase media la ausencia es alarmante: casi 99\%. Muchos de estos jóvenes pierden los vínculos con la Iglesia Católica. Antes estos jóvenes continuaban manteniendo cierta identidad católica gracias a las estructuras de apoyo de una cultura católica. Hoy, en la medida en que avanza la cultura moderna y la cultura posmoderna, impulsadas por los medios de comunicación de masas y el ambiente progresivo de las grandes ciudades, desaparecen la cultura católica y sus estructuras de apoyo. Puede acontecer lo que está sucediendo en Europa, la primera generación no practica la religión y no educa a los hijos en la fe, la segunda no tendrá ninguna referencia de fe cristiana.

Nací en Irlanda pero he pasado la mayor parte de mi vida en América Latina. Por lo tanto, estoy en una posición privilegiada para hacer una comparación entre los dos mundo. Hay una cuestión importante que necesitamos estudiar referente a la increencia juvenil: será que nuestro destino es el mismo de la Iglesia de Europa.

Quiero dar un ejemplo, que es típico de otros países de Europa. En los años 60 Irlanda producía el mayor número de vocaciones religiosas, en el mundo, en proporción con su población. Enviaba misioneros a todos los continentes. La práctica de la misa dominical era de casi un 99\%. En los años 80 la crisis explotó con más fuerza. Sentí esta crisis muy de cerca en mi propia vida. Cuando niño estudié en una escuela de religiosas. Hoy, la escuela ha sido entregada al Estado por falta de vocaciones. Cuando joven estudié en un colegio de religiosos, de una congregación que era responsable de casi 100 escuelas. Hoy, todas las escuelas se pusieron en manos de laicos. Hace años que las dos congregaciones no reciben vocaciones. Entré en una congregación misionera que tenía un promedio de 25 ordenaciones por año. En el seminario mayor éramos 250 seminaristas. Hoy no hay ordenaciones. Otras congregaciones corrieron la misma suerte. En los años 50, en la diócesis de Ossory, donde nací, había tantas vocaciones, que el obispo cerró su seminario durante 10 años para disminuir el número de candidatos. Hoy el seminario está cerrado, no por exceso de vocaciones, sino, por falta de éstas. En 1981 había 114 padres en la dió- 
cesis. En 2004 hay solamente 91. La edad media de los padres es de 57 años. Tampoco hay perspectivas de futuras ordenaciones. Al mismo tiempo, son pocos los jóvenes que participan de la misa dominical y que mantienen vínculos formales con la Iglesia.

Creo que un acontecimiento en los años 60 que puede iluminar las perspectivas de la increencia juvenil en América Latina. En 1962, el arzobispo John McQuaid, arzobispo de Dublín, pidió al Jesuita americano, P. Biever, hacer una investigación ${ }^{11}$ sobre la opinión pública. El resultado mostró que la gran mayoría de la población consideraba a la Iglesia Católica como el líder natural del pueblo y era la fuerza más grande a favor del bien en Irlanda. El Padre Biever descubrió que el país era casi una teocracia en la que toda legislación significativa necesitaba ser aprobada antes por los obispos. No obstante, las señales del futuro estaban presentes en los resultados de la investigación. Desafortunadamente la Iglesia en aquella época no supo ver los signos de los tiempos. Por un lado, la gran mayoría que consideraba a la Iglesia como la fuerza más grande para el bien, era de personas con bajo nivel escolar. Por otro lado, más de un $83 \%$ de las personas con nivel de escolaridad superior no compartía ésta idea y criticaba la manera de ejercer su poder la Iglesia. La Iglesia no fue capaz de leer los signos de los tiempos y prepararse a dar respuesta a la nueva época que estaba naciendo. Hoy en día, la crisis de la iglesia ocurre en un nuevo contexto de crecimiento económico y alto nivel de escolaridad. Más de $66 \%$ de los jóvenes, hoy, tienen nivel de escolaridad superior. En este nuevo contexto la Iglesia sufre ataques continuos de los medios de comunicación de masas y de la sociedad civil que la acusa de abuso de poder, de falta de transparencia, de liderazgo, de abusos sexuales como pedofilia, y la falta de pertenencia para el mundo moderno. Hoy la Iglesia perdió la juventud. Podremos en América Latina evitar caer en la misma trampa.

En América Latina la capacidad de la Iglesia de afrontar la increencia juvenil, va a depender de su capacidad de leer los signos de los tiempos hoy. ¿Será que nuestro modelo de evangelización juvenil en América Latina hoy presupone una masa de personas sin educación y pobre y residiendo en el medio rural? ¿Conseguiremos evangelizar los futuros formadores de opinión pública con un modelo de Iglesia cada vez más clerical?

11 Coogan, Tim Pat, (2003). Ireland in the Twentieth Century, Hutchinson: London, p. 732. 
¿Cuál es la imagen de la Institución que se presenta a los jóvenes? ¿Tiene pertenencia para el mundo de hoy? ¿Estamos dando respuesta a las preguntas de otras épocas y no a las preguntas que están haciendo hoy los jóvenes? Estamos poniendo toda nuestra fe en el futuro de la iglesia en resultados a corto plazo basados en el impacto emocional o en grandes eventos masivos, abandonando el proceso lento de evangelización gradual por etapas a través de un acompañamiento sistemático, personal y grupal. el futuro

Cómo evitar las condiciones que favorecen la increencia juvenil en

La Posmodernidad no reemplaza a la Modernidad, pero corrige algunos desvíos. Las dos culturas conviven juntas. Los valores de la modernidad continúan siendo importantes para los jóvenes: la democracia, el dialogo, la búsqueda de felicidad humana, la transparencia, los derechos individuales, la libertad, la justicia, la sexualidad y la igualdad de la mujeres. Son, especialmente, los valores de los medios universitarios, de los intelectuales y de las grandes ciudades. En el medio universitario el método científico reina supremamente. Es bueno recordar que los jóvenes universitarios, los intelectuales y los profesionales son los formadores de la opinión pública. Ignorarlos es comprometer el futuro de la Iglesia. Es en este medio donde la increencia avanza con más velocidad. Muchos universitarios están abiertos a una dimensión espiritual de la vida, pero desligada de la Iglesia institucional.

La imagen que la Iglesia proyecta en la sociedad es muy importante para la evangelización de la juventud. Inspirada por Medellín y Puebla, la Iglesia de América Latina ha acumulado un gran capital de credibilidad gracias a sus gestos proféticos en el pasado. Puso su fuerza moral al lado de los sectores marginados de la sociedad y fue la voz de las personas sin voz contra gobiernos autoritarios.

No obstante, hay hoy una tendencia a retroceder y fortalecer una Iglesia más clerical y menos profética. Tal tendencia puede acabar en la perdida de este capital y el fortalecimiento de la increencia juvenil. Las vocaciones que atraemos no serán las más idealistas y dinámicas con capacidad de dialogar con el nuevo mundo que nace. Podemos perder los futuros dirigentes y formadores de opinión pública. 
Tal vez la Iglesia del futuro, sea menos numerosa. Lo importante es que ella sea el fermento en la masa que evangeliza, no a partir del poder, sino por el testimonio y dinamismo de sus miembros, de manera especial de los jóvenes. Según la espiritualidad bíblica cuando somos frágiles, entonces somos más fuertes.

\section{Una experiencia bien sucedida}

En América Latina apenas comenzamos a enfrentarnos a la creencia juvenil. Hay un largo camino. Hay muchas experiencias bien secuenciadas. En los últimos años, yo he trabajado, por ejemplo, en un curso para líderes que llamamos 'Curso de Dinámica para Lideres' (CDL)ii que busca integrar elementos de la modernidad y la posmodernidad. Usamos una herramienta de renovación pastoral y para fortalecer la pastoral de conjunto. En Brasil organizamos un curso nacional todos los años y se está aplicando en muchas diócesis del país y en otros países. El año pasado organizamos un curso latinoamericano con la participación de personas de 112 países. Las ventajas de los cursos son varias:

- Puede ser reproducido con facilidad para influir a más gente

- Hay variedad, diversión y un buen espíritu

- Hay garantía de éxito

- Construir utilizando los dones y las habilidades de los participantes

- Los participantes aprenden haciendo

- Método de Entrenamiento: simular la situación real

- Hay un segundo nivel de formación para las personas que son 11amadas de vuelta para trabajar como facilitadores.

- Utiliza técnicas modernas de marketing

- Tiene efecto multiplicador

- Es un curso básico sin el cual no se puede dar otros pasos.

El CDL es apenas una experiencia en medio de una gran variedad de experiencias pastorales que abren puertas y ventanas para percibir diferentes maneras de trabajar la increencia juvenil en un contexto cultural radicalmente diferente de otras épocas. La creatividad pastoral es uno de los motivos porque la increencia no ha penetrado en el medio de los jóvenes latinoamericanos con la misma fuerza que en los países de Europa.

ii Boran (2004). Curso de Dinâmica para Líderes (CDL). Lima: Paulinas. 